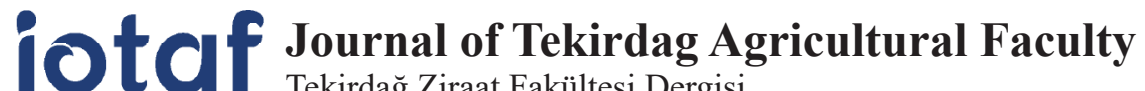 \\ Tekirdağ Ziraat Fakültesi Dergisi
}

Mayis/May 2019, 16(2) Başvuru/Received: 06/02/19 Kabul/Accepted: 05/04/19 DOI: $10.33462 /$ jotaf.521637

http://dergipark.gov.tr/jotaf http://jotaf.nku.edu.tr/

\section{Çilekte Rhizoctonia Kök Çürüklüğü (Rhizoctonia solani)'ne Karşı Bazı Bitki Aktivatörlerinin Etkileri}

The Effects Of Some Plant Activators Against Rhizoctonia Root Rot (Rhizoctonia solani) On Strawberry

\author{
Mustafa AYSAN ${ }^{1}$, Selda KOZAK ÖZDEMİR ${ }^{1}$, Ali ERKILIÇ ${ }^{1 *}$
}

\section{$\ddot{O} \mathbf{z}$}

Çilekte Rhizoctonia solani'nin neden olduğu siyah kök çürüklüğü hastalığına karşı kök ve yapraktan uygulanan bitki aktivatörlerinin (Salisilik asit, Acibenzolar S-Methyl, Messenger, ISR 2000, Crop Set ve Fosetyl-Al) etkisi in vitro ve in vivo denemeleriyle araştırılmıştır. Bitki aktivatörlerinin Rhizoctonia solani’nin miseliyal gelişimine olan etkileri incelendiğinde, Salisilik Asit ve Fosetyl-Al $700 \mu \mathrm{g} / \mathrm{ml}$ 'nin üzerindeki konsantrasyonlarda patojen gelişimini baskılarken diğer bitki aktivatörleri patojene herhangi bir etkide bulunmamıştır. Bitki aktivatörlerinden Salisilik asit, Acibenzolar S-Methyl ve Fosetyl-Al kök daldırma uygulamasında hastalığı \%47-65 arasında baskılarken, yeşil aksama uygulamasında, Messenger ve Fosetyl-Al hastalığı \%59-64 arasında baskılamıştır. Hem kök daldırma hem de yeşil aksam uygulamasında Aliette uygulaması başarılı bulunmuştur. Sonuçta, çilekte Rhizoctonia solani'nin neden olduğu kök çürüklüğü hastalığının entegre mücadelesinde bitki aktivatörlerinin kullanılabileceği bu çalışmayla gösterilmiştir.

Anahtar Kelimeler: Çilek, Rhizoctonia solani, Bitki aktivatörleri ve Fosetyl-Al

\begin{abstract}
The effect of plant activators (Salicylic Acid, Acibenzolar S-Methyl, Messenger, ISR 2000, Crop Set, and Fosetyl-Al) applied to root and leaf was investigated in petri and the greenhouse pot experiments against the black root rot disease caused by Rhizoctonia solani on strawberry. As a result of in vitro studies, Salicylic Acid and Fosetyl-Al up to $700 \mu \mathrm{g} / \mathrm{ml}$ concentration reduced the mycelial development of Rhizoctonia solani, but other plant activators have had no effect on mycelial development of the pathogen. The disease was suppressed between a $47 \%$ and $65 \%$ ratio by the root dipping application of plant activators Salicylic Acid, Acibenzolar S-Methyl, and Fosetyl-Al. Otherwise, the disease was reduced by a 59\% and $65 \%$ ratio by foliar applications of Messenger, and Fosetyl-Al. The best plant acitivator is Fosetyl-Al for foliar and root dipping applications. Finally, it has been proved the efficiency of the use of plant activators at the integrated management of black root rot disease caused by Rhizoctonia solani on strawberry.
\end{abstract}

Keywords: Strawberry, Rhizoctonia solani, Plant activators, and Fosetyl-Al

\footnotetext{
${ }^{1}$ Mustafa Aysan, Çukurova Üniversitesi Ziraat Fakültesi Ziraat Fakültesi, Bitki Koruma Bölümü, Adana, E-mail: mustafaaysan83@gmail.com (i) OrcID: 0000-0002-4262-866X

${ }^{1}$ Selda Kozak Özdemir, Çukurova Üniversitesi Ziraat Fakültesi Ziraat Fakültesi, Bitki Koruma Bölümü, Adana, E-mail: kozakselda@gmail. com (D) OrcID: 0000-0002-0126-0969

1*Sorumlu Yazar/Corresponding Author: Ali Erkılıç, Çukurova Üniversitesi Ziraat Fakültesi Ziraat Fakültesi, Bitki Koruma Bölümü, Adana, E-mail: erkilic@cu.edu.tr (D) OrcID: 0000-0003-0159-2039

Atıf/Citation: Aysan, M., Kozak Özdemir, S., Erkılıç, Ö. Çilekte Rhizoctonia kök çürüklüğü (Rhizoctonia solani)'ne karşı bazı bitki aktivatörlerinin etkileri. Tekirdağ Ziraat Fakültesi Dergisi, 16(2), 173-180.

(CBu çalışma Tekirdağ Namık Kemal Üniversitesi tarafından Creative Commons Lisansı (https://creativecommons.org/licenses/by-nc/4.0/) kapsamında yayınlanmıştır. Tekirdağ 2019
} 


\section{Extendend Summary}

Rhizoctonia solani, a fungal agent of soil borne, causes black root rot disease in strawberry. This disease causes serious problems in strawberry production areas in our country. In this study, the effect of plant activators (Salicylic acid, Acibenzolar S-Methyl, Messenger, ISR 2000, Crop Set and Fosetyl-Al) applied to root and foliar against black root rot disease in strawberry was investigated in in vitro and in vivo. Tolclophos methyl fungicide was used as a control in the study.

The effect of 10 different concentrations of $0-1000 \mu \mathrm{g} / \mathrm{ml}$ of plant activators on the mycelial growth of Rhizoctonia solani in PDA medium was investigated. Messenger and Crop-Set did not make a difference even at a concentration of $1000 \mu \mathrm{g} / \mathrm{ml}$ to the mycelial development of Rhizoctonia solani. ISR-2000 encouraged mycelial development compared to control. Although ASM was not a significant association between increased concentrations, it decreased mycelial development compared to control. SA and Fosetyl-Al decreased mycelial development of Rhizoctonia solani due to increased doses; SA $700 \mu \mathrm{g} / \mathrm{ml}$, Fosetyl-Al 800 $\mu \mathrm{g} / \mathrm{ml}$ concentrations are completely prevented pathogen development. Tolchlophos-methyl, which is used as a comparison application, is different from plant activators and has fungicidal properties and therefore the effect is directly on the fungus. Therefore, it has a significant impact on fungal development in vitro. Tolchlophos-methyl 's $5 \mu \mathrm{g} / \mathrm{ml}$ concentration completely blocked to mycelial development pathogen.

The effects of plant activators on Rhizoctonia solani were tested in 2 different ways as root dipping and green spraying in the commonly grown Rubygem cultivar. In addition, two morphologically distinct isolates (isolate-1 and isolate-3) of Rhizoctonia solani were used in the study. In the root dipping application, SA, ASM, Fosetyl- Al and Tolchlophos methyl showed the best results in the experiment with isolate 1. The effectiveness of these applications ranged from 47.1 to $64.7 \%$. Fosetyl- Al, Tolchlophos methyl, SA, Messenger and Crop-Set showed the best results in the experiment with isolate 3 . The effectiveness of these application was 56.4-64.1\%. In green spray application, Messenger and Fosetyl- Al have been more effective applications compared to others in both trials with Isolate 1 and Isolate 3 . These applications prevented the disease by $50.0 \%$ and $44.1 \%$ for isolate 1, whereas the rate of inhibition was $59.0 \%$ and $64.1 \%$ in isolate 3 . Fosetyl- Al was found to be the most successful application in both root dipping and green parts.

In conclusion, it was found in this study that plant activators can be used in the integrated management of root rot disease caused by Rhizoctonia solani in strawberry. 
Dünya'da, çilekte fungal hastalıklar, üretim bölgelerinde önemli ölçüde ekonomik kayıplara neden olmaktadırlar. Bu hastalıklar, çilek yetiştiriciliği yapılan alanlarda yetişme dönemi boyunca bitkilerin tüm organlarında hastalık yaparak Dünya'da, önemli ölçüde ekonomik kayıplara neden olmaktadırlar. Bitkileri fide döneminde enfekte ederek, erken dönemde ölüme neden olmakta, veya çiçeklenme döneminde çiçekleri hastalandırarak çiçeklerin kurumasına neden olmaktadır. Bunun sonucu olarak da bitkinin önemli oranda meyve tutumunu engellemekte, diğer bir kısmı da bitkilerde sistemik enfeksiyona neden olarak bitkilerde gelişme geriliğine, solgunluğa ve bitkinin tamamen ölümüne sebep olmaktadırlar. Bu tip enfeksiyonların pek çoğunda hasta bitkinin tüm organları hastalık etmeniyle tohum/ toprak yoluyla bulaşmaktadır (Ünlü ve Boyraz, 2010). Pazar ve marketlerde tüketime sunulan meyvelerde de hastalıklardan dolayı kalite kayıplarına sıkça rastlamak mümkündür. Bu bozulmaların büyük bir kısmından sorumlu olan mikroorganizmaların pek çoğu fungal kökenli olmaktadır.

Çilek veriminde önemli ekonomik kayıpların nedeni olan siyah kök çürüklüğü hastalığı farklı fungal etmenlerin neden olduğu kompleks bir hastalıktır (Wing ve ark., 1994). Siyah kök çürüklüğü hastalığına sebep olan patojenler arasında Rhizoctonia spp., Fusarium spp., Pythium spp., Cylindrocarpon sp., Verticilium sp., Alternaria sp., Aspergillus spp. bulunmaktadır. Bu hastalığa neden olan etmenlerin fide ve tarla üretim sistemlerine bulaşık materyal ile girdiği bilinmektedir (Abad ve ark., 2002; Martin, 2000). Rhizoctonia fragariae (Husain ve McKeen, 1963) ve Rhizoctonia solani Kühn (Leandro ve ark., 2004; Ferguson ve ark., 2002) çilek bitkilerinde siyah kök çürüklüğü hastalık etmenleridir.. Hastalık belirtileri çileğin meyve, taç, kök, yaprak ve çiçek tomurcuklarında görülmekte ve çilek üretiminde ekonomik kayıplara neden olmaktadır. Yürüten ve ark., (1986) kök çürüklüğü hastalığının Akdeniz Bölgesinde çileklerde önemli sorunlara yol açtığını, hastalık nedeniyle \%40-60 oranında bitkinin öldüğünü bildirmiştir.

Uzun yıllardan beri bitki hastalıklarıyla sürdürülen kimyasal mücadele sonucu ortaya çıkan ciddi sorunlardan dolayı, özellikle gelişmiş ülkelerde başlayan, kimyasal mücadeleye alternatif yöntemlerin araştırılma çabasına girişilmiştir. Çilekte olduğu gibi pek çok üründe yoğun pestisit kullanılması sonucu doğal denge tahrip olmuş, çevre ve insan sağlığını tehdit eder duruma gelmiştir (Delen ve Özbek, 1993; Delen ve Tosun, 1997). Yaşanan olumsuzlukların en aza indirilmesinde kimyasal mücadele yöntemlerine alternatif dayanıklılık teşvik edici ürünlerin kullanımı popüler olmuştur. Bu ürünlerden biri olan bitki aktivatörleri bitkinin doğal savunma mekanizmasını uyararak bitki hastalıklarına karşı pratik bir mücadele olanağı sağlamaktadır.

Bitki aktivatörleri, bitkilerin sistemik kazanılmış dayanıklık (SAR) ve uyarılmış sistemik dayanıklık (ISR) mekanizmalarıyla hastalıklara karşı dayanıklılık göstermelerini sağlamaktadır. SAR mekanizmasında; patojen, bitkiyi hormon (salisilik asit ve jasmonik asit) ve PR proteini üretmesi için; ISR mekanizmasında ise patojen olmayan bir uyarıc1, bitkiyi patojenleri etkisiz hale getirmek için fitoaleksin, bitki hücre güçlendiricileri vs. üretimi konusunda uyarmaktadır (Sequeira, 1983).

Bu çalışmada, çilekte toprak kökenli patojenlerden Rhizoctonia solani'nin neden olduğu siyah kök çürüklüğü hastalığına karşı bitki aktivatörü ve organik/inorganik gübrelerin etkisinin ortaya konulması amaçlanmıştır. Bu amaç doğrultusunda bitkilerin hastalıklara karşı dayanıklılığını uyaran, yedi adet bitki aktivatörünün etkileri, in vitro ve in vivo' da araştırılmıştır.

\section{In vitro Testler}

\section{Materyal ve Yöntem}

Dayanıklılığı teşvik edici bitki aktivatörleri ile yürütülen çalışmada, Salisilik asit (SA), Acibenzolar S-Methyl (ASM), Messenger (M), Lactobasillus acidophilus fermantasyon ürünü ISR 2000 (ISR) ve Crop Set (CS) ile Fosetyl-Al (FA) kullanılmıştır. Ayrıca R. solani mücadelesinde yaygın kullanımı olan Tolclophos methyl (TM) fungisiti karşılaştırma amacıyla denemede yer almıştır. Bu kimyasalların PDA besi ortamında Rhizoctonia solani'nin miselyal gelişimine olan etkilerini belirlemek amacıyla 100-1000 $\mu \mathrm{g} / \mathrm{ml}$ arasındaki konsantrasyonları denenmiştir. Bu amaçla, cam tüplerin her birine $10 \mathrm{ml}$ PDA ortamı hazırlanarak otoklav edilmiş ve sterilizasyon işlemi bittiğinde bu tüpler $50^{\circ} \mathrm{C}$ 'deki su banyosu içerisine yerleştirilmiştir. Diğer yandan steril su içerisinde, denemelerde kullanılmış olan aktivatörlerin stok solüsyonları hazırlanmıştır. Daha sonra su banyosunda sıcaklı̆̆ $50^{\circ} \mathrm{C}^{\prime}$ ye inmiş olan deney tüplerindeki PDA ortamlarına stok solüsyonlarından $100-1000 \mu \mathrm{g} / \mathrm{ml}$ arasındaki konsantrasyonlarda kimyasallar bulunacak şekilde, otomatik mikropipetlerle çekilerek injekte edilmiş ve bu tüplerdeki ortamlar tüp çalkalayıcı ile homojenize edilerek 9 cm’lik steril Petri kaplarına dökülmüştür.

Petrilerdeki ortamların katılaşmasının ardından $R$. solani'nin PDA ortamında geliştirilmiş 4-5 günlük taze kültürlerinden alınan 6 mm'lik diskler kimyasal eklenmiş ortamlara ekilmiştir. Bu Petriler $24^{\circ} \mathrm{C}^{\prime}$ de karanlık ortamda inkube edilmiş, 5 gün sonra gelişen kolonilerin çapları ölçülerek kaydedilmiştir. 


\section{In Vivo Testler \\ Kök Daldırma Uygulamaları}

Fide ilaçlamaları, denemelerde kullanılmış bitki aktivatörlerinin sulu süspansiyonları ve bu süspansiyonlara fidelerin daldırılması şeklinde yapılmıştır. Bu çalışmada kök infeksiyonları ile Rhizoctonia solani'ye karşı duyarlılıkları belirlenmiş ve yaygın yetiştiriciliği yapılan Rubygem çeşidi kullanılmıştır. Aynı zamanda dayanıklılığı teşvik edici kimyasalların bazı ürünlerde ruhsatlı kullanım dozları göz önüne alınarak belirlenen dozları kullanılmıştır (Çizelge 1). Bunun için kimyasalların bu dozları plastik beherler içerisinde hazırlanmış ve çilek fideleri 1 dakika süreyle bu süspansiyona daldırılmıştır. Daha sonra, içerisinde 1:1 oranında tarla toprağı-kum karışımı bulunan $10 \mathrm{~cm}$ çaplı plastik saksılara yarıya kadar bu karışım doldurulmuş, daha sonra kökleri kesilerek dikime hazır hale getirilen çilek fideleri, her saksıya 1 fide olacak şekilde dikilmiştir.

Çizelge 1. Saksı Çalışmalarında Kullanılan Bitki Aktivatörlerinin Kullanım Dozları

Table 1. Dose of Plant Activators Used in Pot Application

\begin{tabular}{ccc}
\hline Uygulama Şekli ve Dozu & $\begin{array}{c}\text { Daldırma } \\
(1001 \mathrm{su})\end{array}$ & $\begin{array}{c}\text { Yeşil Aksam Püskürtme } \\
(1001 \mathrm{su})\end{array}$ \\
\hline SA & $100 \mathrm{~g}$ & $100 \mathrm{~g}$ \\
ASM & $50 \mathrm{~g}$ & $50 \mathrm{~g}$ \\
Messenger & $10 \mathrm{~g}$ & $10 \mathrm{~g}$ \\
Fosetyl-Al & $200 \mathrm{~g}$ & $200 \mathrm{~g}$ \\
ISR & $100 \mathrm{ml}$ & $100 \mathrm{ml}$ \\
Crop Set & $200 \mathrm{ml}$ & $200 \mathrm{ml}$ \\
Tolclophos Methyl & $400 \mathrm{~g}$ & $400 \mathrm{~g}$
\end{tabular}

Fidelerin dikim çukuruna, dikimle birlikte Rhizoctonia solani’nin 5 haftalık kum-mısır unu (\%96 kum-\%4 mısır unu-\%20 su v/w) kültüründen her saksıya, patojenite testi ile belirlenmiş olan, 10g inokulum uygulanmıştır (Biçici ve Erkılıç, 1986). Kontrol saksılardaki fideler sadece suya daldırılarak ve Rhizoctonia solani'nin aynı miktar inokulumu uygulanmıştır. Bu çalışmada patojenin 2 farklı izolatı kullanılmıştır. Bu şekilde hazırlanan saksılar sera koşullarında yerleştirilmiş ve dikimden 4-8 hafta sonra saksılardan bitkiler sökülerek, bitkilerin kökleri incelenerek infekteli kök oranı belirlenmiştir. Denemenin her bir uygulamasında 5 tekerrür ve her bir tekerrürde 2 saksı kullanılmıştır.

İnfekteli kök oranını belirlemek için her bitkinin kökleri infekteli ve sağlam olarak sayılmıştır. Kök infeksiyonlarının şiddetini değerlendirmek için görsel bir skala geliştirilmiştir (Çizelge 2). Hastalık şiddeti değerlendirmesi Townsend-Heuberger; \% etki değerlendirmesi ise Abbot formülüne göre yapılmıştır (Townsend and Heuberger, 1973; Abbot, 1925).

Çizelge 2. Hastalık Değerlendirme Skalası

Table 2. Disease Evaluation Scale

\begin{tabular}{cc}
\hline Görsel İnfekteli Kök Oranı & Skala Değeri \\
\hline 0 & 0 \\
\hline İz miktar & 1 \\
\hline 1/4'ü & 2 \\
\hline 1/2'si & 3 \\
\hline 3/4'ü & 4 \\
\hline 3/4'den fazla & 5 \\
\hline
\end{tabular}

Yeşil Aksam Uygulamaları

Çalışmanın bu bölümünde bitki aktivatörlerinin Rhizoctonia solani'nin çilek bitkilerinde hastalık oluşturması üzerine etkileri, yeşil aksam ilaçlamaları ile belirlenmiştir. Bu amaçla önce içerisinde 1:1 oranında tarla toprağı- 
kum karışımı bulunan $10 \mathrm{~cm}$ çaplı plastik saksılara yarıya kadar bu karışım doldurulmuş, daha sonra kökleri kesilerek dikime hazır hale getirilen çilek fideleri, her saksıya 1 fide olacak şekilde dikilmiştir. Fidelerin dikim çukuruna, dikimiyle birlikte Rhizoctonia solani'nin 5 haftalık kum-mısır unu (\%96 kum-\%4 mısır unu-\%20 su v/w) kültüründen her saksıya $10 \mathrm{~g}$ inokulum uygulanmıştır. Bu şekilde hazırlanan bitkiler sera koşullarında tutulmuştur. Bitkilerde yeni yaprak oluşumu başladığında, dayanıklılık teşvik edicilerin farklı konsantrasyonları, bitkilere yeşil aksama püskürtme şeklinde uygulanmıştır. Bitkilere 1 hafta kadar sonra tekrar aynı dozlarda kimyasal uygulamaları yapılmıştır. Kontrol saksılardaki bitkilerin yeşil aksamına sadece su pulverize edilmiştir. Dikimden 4-8 hafta sonra saksılardan bitkiler sökülerek, bitkilerin kökleri incelenerek infekteli kök oranı belirlenmiştir. Denemenin her bir uygulamasında 5 tekerrür ve her bir tekerrürde 2 saksı kullanılmıştır.

\section{İstatistik Analiz}

In vitro ve in vivo denemeler sonucunda elde edilen değerler üzerinden uygulamaların birbirlerinden farklılığ varyans analizi ve ortalamalar arasındaki farklılıklar ise LSD (0.05) çoklu karşılaştırma testine göre yapıllmıştır.

\section{Bulgular}

\section{Bitki Aktivatörlerinin In vitro'da Rhizoctonia solani'nin Miseliyal Gelişmesi Üzerine Etkileri}

Bitki aktivatörlerinin in vitro'da Rhizoctonia solani'nin miseliyal gelişmesi üzerine etkileri 100-1000 $\mu \mathrm{g} / \mathrm{ml}$ arasında 10 farklı konsantrasyonda test edilmiştir. Kontrol Petrilerde ortama herhangi bir kimyasal ilave edilmezken, karşılaştırma amaçlı kullanılan tolchlophos methyl $1 \mu \mathrm{g} / \mathrm{ml}$ konsantrasyona kadar kullanılmıştır. Çalışmada, Messenger ve Crop-Set Rhizoctonia solani'nin miseliyal gelişmesinde kontrole göre $1000 \mu \mathrm{g} / \mathrm{ml}$ konsantrasyonda bile bir farklılık yaratmazken, Isr-2000'de kontrole göre miseliyal gelişme az da olsa teşvik edilmiştir (Çizelge 3). ASM'de artan konsantrasyonlar arasında önemli bir ilişki olmasa da kontrole göre miseliyal gelişme azaltılmıştır. SA ve Fosetyl-Al ise artan dozlara bağlı olarak Rhizoctonia solani’nin miseliyal gelişmesini azaltmış, SA'da 700 $\mu \mathrm{g} / \mathrm{ml}$, Fosetyl- Al'de ise $800 \mu \mathrm{g} / \mathrm{ml}$ konsantrasyonda patojen gelişmesi tamamen engellenmiştir.

Çizelge 3. Kimyasalların Farklı Konsantrasyonlarının Rhizoctonia solani’nin Miseliyal Gelişmesine Etkileri (Koloni çapı-mm)

Table 3.The Effects of Different Concentrations of Chemicals on the Development of Rhizoctonia solani (Colony diameter-mm)

\begin{tabular}{cccccccc}
\hline Konsantrasyon & ASM & SA & M & CS & ISR & FA & TM \\
\hline $0 \mu \mathrm{g} / \mathrm{ml}$ & $66,4 \mathrm{e}^{*}$ & $66,4 \mathrm{~d}$ & $66,4 \mathrm{a}$ & $66,4 \mathrm{a}$ & $66,4 \mathrm{a}$ & $66,4 \mathrm{f}$ & $66,4 \mathrm{~b}$ \\
\hline $100 \mu \mathrm{g} / \mathrm{ml}$ & $42,7 \mathrm{bc}$ & $49,2 \mathrm{c}$ & $68,5 \mathrm{a}$ & $65,6 \mathrm{a}$ & $72,7 \mathrm{~b}$ & $44,5 \mathrm{e}$ & $0 \mathrm{a} *$ \\
\hline $200 \mu \mathrm{g} / \mathrm{ml}$ & $45,9 \mathrm{~d}$ & $32,3 \mathrm{~b}$ & $66,2 \mathrm{a}$ & $68,9 \mathrm{a}$ & $71,0 \mathrm{~b}$ & $32,9 \mathrm{~d}$ & $0 \mathrm{a}$ \\
\hline $300 \mu \mathrm{g} / \mathrm{ml}$ & $44,6 \mathrm{~cd}$ & $25,0 \mathrm{~b}$ & $65,0 \mathrm{a}$ & $65,1 \mathrm{a}$ & $72,5 \mathrm{~b}$ & $28,5 \mathrm{~d}$ & $0 \mathrm{a}$ \\
\hline $400 \mu \mathrm{g} / \mathrm{ml}$ & $41,4 \mathrm{~b}$ & $20,4 \mathrm{~b}$ & $63,0 \mathrm{a}$ & $69,5 \mathrm{a}$ & $72,4 \mathrm{~b}$ & $23,2 \mathrm{c}$ & $0 \mathrm{a}$ \\
\hline $500 \mu \mathrm{g} / \mathrm{ml}$ & $37,3 \mathrm{a}$ & $5,2 \mathrm{a}$ & $69,2 \mathrm{a}$ & $71,9 \mathrm{a}$ & $70,9 \mathrm{~b}$ & $14,8 \mathrm{~b}$ & $0 \mathrm{a}$ \\
\hline $600 \mu \mathrm{g} / \mathrm{ml}$ & $43,9 \mathrm{bcd}$ & $4,4 \mathrm{a}$ & $70,9 \mathrm{a}$ & $67,6 \mathrm{a}$ & $70,4 \mathrm{~b}$ & $4,5 \mathrm{a}$ & $0 \mathrm{a}$ \\
\hline $700 \mu \mathrm{g} / \mathrm{ml}$ & $42,8 \mathrm{bc}$ & $0 \mathrm{a}$ & $74,0 \mathrm{a}$ & $59,2 \mathrm{a}$ & $71,6 \mathrm{~b}$ & $2,3 \mathrm{a}$ & $0 \mathrm{a}$ \\
\hline $800 \mu \mathrm{g} / \mathrm{ml}$ & $41,5 \mathrm{~b}$ & $0 \mathrm{a}$ & $71,0 \mathrm{a}$ & $67,8 \mathrm{a}$ & $73,7 \mathrm{~b}$ & $0 \mathrm{a}$ & $0 \mathrm{a}$ \\
\hline $900 \mu \mathrm{g} / \mathrm{ml}$ & $43,1 \mathrm{bcd}$ & $1,1 \mathrm{a}$ & $72,9 \mathrm{a}$ & $68,9 \mathrm{a}$ & $74,0 \mathrm{~b}$ & $0 \mathrm{a}$ & $0 \mathrm{a}$ \\
\hline $1000 \mu \mathrm{g} / \mathrm{ml}$ & $42,1 \mathrm{bc}$ & $0 \mathrm{a}$ & $71,5 \mathrm{a}$ & $68,9 \mathrm{a}$ & $71,8 \mathrm{~b}$ & $0 \mathrm{a}$ & $0 \mathrm{a}$ \\
\hline
\end{tabular}

Karşılaştırma uygulaması olarak denemede yer alan Tolchlophos-methyl, Rhizoctonia türlerinin neden olduğu hastalıklara karşı ruhsatlı olarak kullanılmaktadır. Tolchlophos methyl'in $100 \mu \mathrm{g} / \mathrm{ml}$ konsantrasyonunda miseliyal gelişme tamamen engellenmiştir. Bunun üzerine miseliyal gelişmenin engellendiği minimum konsantrasyonu görebilmek için 1-100 $\mu \mathrm{g} / \mathrm{ml}$ arası konsantrasyonlar denenmiş ve miseliyal gelişmenin $5 \mu \mathrm{g} / \mathrm{ml}$ konsantrasyonda tamamen engellendiği görülmüştür.

\section{Bitki Aktivatörlerinin Rhizoctonia solani’nin Hastalık Oluşturması Üzerine Etkileri}

Bitki aktivatörlerinin Rhizoctonia solani’nin çilek bitkilerinde hastalık oluşturması üzerine etkileri, yaygın yetiştiriciliği yapılan Rubygem çeşidinde kök daldırma ve yeşil aksam püskürtme olarak 2 farklı şekilde denenmiştir.

Çalışmada kullanılan R. solani'nin iki izolatı da kontrol uygulamada birbirlerine yakın değer göstermiş ve hastalık şiddeti izolat 1'de \%56.7, izolat 3'de ise \%65 olarak hesaplanmıştır (Çizelge 4). İzolat 1 kullanılarak yürütülen kök daldırma çalışmasında SA, ASM, Fosetyl-Al ve Tolchlophos methyl en iyi ve istatistiksel olarak 
benzer sonucu vermiştir. Bu uygulamalarda hastalık şiddeti \%20.0 ila 30.0 arasında değişirken, uygulamaların Abbott'a göre etkinliği \%47,1 ila 64,7 arasında değişmiştir. İzolat 3 ile yürütülen denemede ise Fosetyl-Al, Tolchlophos methyl ve SA yine en iyi sonucu verenler olurken, Messenger ve Crop-Set de bu gruba dahil olmuştur. $\mathrm{Bu}$ uygulamalarda hastalık şiddeti $\% 23,3$ ila 28.3 arasında değişirken, uygulamaların etkinliği \% 56.4-64.1 arasında gerçekleşmiştir. İzolat 3'de Messenger ve Crop-Set infeksiyonları azaltmak adına daha iyi bir performans sergilerken, diğer uygulamalar her iki izolatta da benzer olmuştur.

Çizelge 4. Kimyasalların Kök Daldırma Uygulamalarının Rhizoctonia solani'nin Hastalık Oluşturması Üzerine Etkileri

Table 4.The Effects of Root Dipping Applications on the Disease of Rhizoctonia solani

\begin{tabular}{ccccccc}
\hline Izolat No & \multicolumn{3}{c}{ İzolat 1 } & \multicolumn{3}{c}{ Izolat 3 } \\
\hline Uygulama & $\begin{array}{c}\text { Hastalık } \\
\text { Şiddeti (\%) }\end{array}$ & \% Etki & $\begin{array}{c}\text { Hastalık } \\
\text { Şiddeti (\%) }\end{array}$ & \% Etki \\
\hline SA & 23,3 & a & 58,8 & 28,3 & ab & 56,4 \\
\hline ASM & 30,0 & a & 47,1 & 38,3 & bc & 41,0 \\
\hline Messenger & 43,3 & b & 23,5 & 25,0 & a & 61,5 \\
\hline Fosetyl-Al & 20,0 & a & 64,7 & 23,3 & a & 64,1 \\
\hline ISR-2000 & 45,0 & b & 20,6 & 43,3 & c & 33,3 \\
\hline Crop-Set & 50,0 & bc & 11,8 & 26,7 & a & 59,0 \\
\hline Tolchlophos methyl & 30,0 & a & 47,1 & 25,0 & a & 61,5 \\
\hline Kontrol & 56,7 & c & & 65,0 & d &
\end{tabular}

Yeşil aksam püskürtme uygulamasında hem İzolat 1, hem de İzolat 3 ile yürütülen çalışmalarda Messenger ve Fosetyl-Al diğerlerine göre daha etkili olarak tespit edilirken, Crop-set ise daha düşük etkide tespit edilmiştir (Çizelge 5). Messenger ve Fosetyl-Al uygulamalarında hastalık şiddeti İzolat 1 için \%28.3 ve 31.7 olurken, bu uygulamaların hastalığı engelleme oranı \% 50.0 ve 44.1 olarak belirlenmiştir. İzolat 3'de hastalık şiddeti biraz daha düşük olmuş (Messenger \%26.7, Fosetyl-Al \%23.3) ve sırasıyla her iki uygulamanın infeksiyonları engelleme oranı \%59.0 ve 64.1 olarak bulunmuştur. Yine kimyasalların yeşil aksama uygulanmasında karşılaştırma amacıyla denemeye alınan Tolchlophos methyl'in de etkisi daldırma uygulamasından daha az olmuştur.

Çizelge 5. Kimyasalların Yeşil Aksam Püskürtme Uygulamalarının Rhizoctonia solani'nin Hastalık Oluşturması Üzerine Etkileri

Table 5. The Effects of Spray Applications of Chemicals on Rhizoctonia solani Disease

\begin{tabular}{ccccccc}
\hline İzolat No & \multicolumn{3}{c}{ İzolat 1 } & \multicolumn{3}{c}{ İzolat 3 } \\
\hline Uygulama & $\begin{array}{c}\text { Hastalık } \\
\text { Şiddeti (\%) }\end{array}$ & \% Etki & $\begin{array}{c}\text { Hastalık } \\
\text { Şiddeti (\%) }\end{array}$ & \% Etki \\
\hline SA & 36,7 & $\mathrm{ab}$ & 35,3 & 41,7 & $\mathrm{~b}$ & 35,9 \\
\hline ASM & 36,7 & $\mathrm{ab}$ & 35,3 & 41,7 & $\mathrm{~b}$ & 35,9 \\
\hline Messenger & 28,3 & $\mathrm{a}$ & 50,0 & 26,7 & $\mathrm{a}$ & 59,0 \\
\hline Fosetyl-Al & 31,7 & $\mathrm{a}$ & 44,1 & 23,3 & $\mathrm{a}$ & 64,1 \\
\hline ISR-2000 & 46,7 & $\mathrm{bc}$ & 17,6 & 48,3 & $\mathrm{bc}$ & 25,6 \\
\hline Crop-Set & 51,7 & $\mathrm{c}$ & 8,8 & 55,0 & $\mathrm{~cd}$ & 15,4 \\
\hline $\begin{array}{c}\text { Tolchlophos } \\
\text { methyl }\end{array}$ & 40,0 & $\mathrm{~b}$ & 29,4 & 38,3 & $\mathrm{~b}$ & 41,0 \\
\hline Kontrol & 56,7 & $\mathrm{c}$ & & & & \\
\hline
\end{tabular}




\section{Tartışma}

Bitki aktivatörlerinin in vitro'da etkisi incelendiğinde SA ve Fosetyl-Al artan dozlara bağlı olarak Rhizoctonia solani'nin miseliyal gelişmesini azaltmış, SA'da $700 \mu \mathrm{g} / \mathrm{ml}$, Fosetyl-Al'de ise $800 \mu \mathrm{g} / \mathrm{ml}$ konsantrasyonda patojen gelişmesi tamamen engellenmiştir Tolchlophos methyl'de ise $100 \mu \mathrm{g} / \mathrm{ml}$ konsantrasyonunda miseliyal gelişme tamamen engellenmiştir.

Çalışmanın in vivo kısmında yapılan kök daldırma uygulamasında, izolat 1 ile yürütülen denemede SA, ASM, Fosetyl-Al ve Tolchlophos methyl en iyi sonucu vermiştir. Bu uygulamaların etkinliği \%47,1 ila 64,7 arasında değişmiştir. İzolat 3 ile yürütülen denemede Fosetyl-Al, Tolchlophos methyl ve SA yine en iyi sonucu verenler olurken, Messenger ve Crop-Set de bu gruba dahil olmuştur. Bu uygulamaların etkinliği \% 56.4-64.1 arasında gerçekleşmiştir. Yeşil aksama püskürtme uygulamasında, hem İzolat 1, hem de İzolat 3 'ile yürütülen çalışmalarda Messenger ve Fosetyl-Al diğerlerine göre daha etkili uygulamalar olmuştur. İzolat 1 'de bu uygulamalar hastalı̆̆ $\% 50.0$ ve 44.1 oranında engellerken İzolat 3 ’te engelleme oran1 \%59.0 ve 64.1 olarak bulunmuştur.

Bitki aktivatörlerinin in vitro'da fungusların miseliyal gelişmesine önemli etkilerinin olmadı̆̆ pek çok çalışmada gösterilmiştir (Lucon ve.ark., 2010; Galdeano ve.ark., 2010, Şahbaz ve Akgül, 2016). Hatta bu aktivatörlerin bazılarının protein yapısında bileşikler içermesi nedeniyle, fungusa besin teşkil etmesi olasılığı bile bulunmaktadır. Bitki aktivatölerinin patojenler üzerine etkisi dolaylı yoldan olmaktadır. Bunlar bitkide dayanıklılık mekanizmasını uyarmakta ve bu yolla fitoaleksinlerin oluşumu sitümüle etmektedirler. Ayrıca bitkinin ürettiği fitoaleksinler ve fenol yapısındaki diğer bazı maddeler patojen infeksiyonuna karşı koyarak patojen gelişmesini engellemektedirler. (Koç ve Üstün 2008).

Şahbaz ve Akgül (2016) tarafından yapılan bir çalışmada, in vitro'da Fusarium oxysporum f. sp. vasinfectum ve Verticillium dahliae üzerinde Fosetyl-Al, ASM ve ISR 2000 kimyasallarının herhangi bir etkisi görülmezken, in vivo' da \% 20- 66,3 oranlarında hastalığı azaltıcı etkisi ölçülmüştür. Bitki aktivatörleri kullanılarak yapılan başka bir çalışmada, in vivo koşullarda, çilekte Rhizoctonia solani üzerinde ASM (Bion 50)'nin Tolchlophos methyl ile aynı etkiyi gösterdiği ve patojen üzerinde çok etkili olduğu bildirilmiştir (El-Fiki ve ark., 2007).

Günümüzde, pestisit kullanımının azaltılması ve alternatif mücadele yöntemlerinin değerlendirilmesi konuları ile ilgili araştırmalar devam etmektedir. Yapılan bu çalışma ile çilekte Rhizoctonia solani’nin neden olduğu kök çürüklüğü hastalığının entegre mücadelesinde, bitki aktivatörlerinin kullanılabileceği ortaya konulmuştur. 


\section{Kaynaklar}

Abad, Z. G., Louws, F. J., Fernandez, G. E., Ferguson, L.M. 2002. Predominance and pathogenicity of fungi and stramenopiles associated with black root rot of strawberries. Phytopathology 92S1.(Abstr.).

Abbott, W.S., 1925. A method of computing the effectiveness of an insecticide.Journal Economy Entomol. 18:265-267.

Biçici, M. ve Erkılıç, A., 1986. Patateste siyah kabukluluk ve gövde kanseri yapan Rhizoctonia solani Kühn'nin integre kontrolü. Doğa Tr. Tar. Or. Der, 10(2), 149-173.

Delen, N. ve Özbek, T. 1993. Pestisitlerin çevre kirlenmesindeki rolleri. I. Ulusal Ekolojik ve Çevre Kongresi, 5-7 Ekim, İzmir.

Delen, N. ve Tosun, N. 1997. Türkiye'de pestisit kullanımının toksikolojik değerlendirilmesi. II. Ulusal

El-Fiki, A. I. I., El-Habaa, G., Flaifel, S. M. A., Hafez, M. A., Abdel-Ghany, R. E. A. 2007. Response of strawberry plants to some abiotic inducers under stress of some root rot pathogens. Annual Agriculture Science, Moshtohor, 45(4), 1407-1417.

Ferguson, L.M., Louws, F.J., Fernandez, G.E., Brannen, P.M., Poling, E.B., Sydorovych, O.B., Safley, C.D., Monks, D.W., Vanesbroeck, Z. Pesic., Sanders, D.C., Smith, J.P. 2002. Chemical and biological alternatives to methyl bromide for strawberry in the southeastern U.S. Proc.of the Int. Res. Conf.on Methyl Bromide Alternatives and Emissions Reduction, 103/1-103/4.

Galdeno, D. M., Guzzo, S. D., Patricio, F. R. A., Harakava, R. 2010. Protection of coffee plants against Brown eye spot by acibenzolar-S-methyl and harpin protein. Pesq. Agropec bras., Brasilia, Vol. 5(7);686-692.

Husain, S. S. and Mckeen, W.E. 1963. Rhizoctonia fragariae in relation to Strawberry degeneration in Southwestern Ontario. Phytopathology, 53(5); 532-540.

Koç, E. ve Üstün, A. S. 2008. Patojenlere Karşı Bitkilerde Savunma ve Antioksidanlar. Erciyes Üniversitesi Fen Bilimleri Enstitüsü Fen Bilimleri Dergisi, 24(1), 82-100.

Leandro, L., Ferguson, L., Fernandez, G., Louws, F. 2004. Integration of biological control for management of strawberry root rot. Annual International Research Conference on Methyl Bromide Alternatives and Emissions Reductions, 89/1-3.

Lucon, C. M. M., Guzzo, S. D., De Jesus, C. O., Pascholati, S. F., De Goes, A. 2010. Postharvest harpin or Bacillus thuringiensis treatments suppress citrus black spot in 'Valencia' oranges. Crop Protection, Vol.29; pp.766-772.

Martin, F.N. 2000. Rhizoctonia spp. recovered from strawberry roots in central caostal California. Phytopathology, 90:345-353.

Sequeira, L. 1983. Mechanisms of induced resistance in plants. Annual Rev. Microbiol., 37:51-79.

Şahbaz, S. and Akgül, D. S. 2016. Fungal Wilt Pathogens and Their Management in Cotton Growing Areas in Reyhanlı County (Hatay). The Journal of Turkish Phytopathology, 45(1), 31-43.

Townsend G-K. Heuberger JW 1943. Methods for Estimating Losses Caused by Diseases in Fungicide Experiments Plant Diasease Report $27: 340-343$.

Ünlü, M. H., ve Boyraz, N. 2010. Konya İlinde Tüketime Sunulan Meyve Ve Sebzelerde Patojen Fungal Flora Ve Bulunuş Oranlarının Belirlenmesi. Selçuk Tarım Bilimleri Dergisi, 24(1), 70-79.

Wing, K.B., Pritts, M.P., Wilcox, W.F. 1994. Strawberry black root rot: A review. Adv. Strawberry Res., 13:13-19.

Yürüten, H., Çınar, A., Çınar, Ö. 1986. Çilek Kök Çürüklüğüne Neden Olan Etmenin ve Etkili Antagonistlerinin Saptanması, Hastalık Çıkışı Üzerine Toprak Solarizasyonunun Etkisinin Araştırılması. Türkiye 1. Biyolojik Mücadele Kongresi Bildirileri (12-14 Şubat 1986, Adana): 447-456. 